\title{
KONTESTASI PRO DAN KONTRA RITUAL PETIK LAUT PADA MASYARAKAT NELAYAN PUGER JEMBER
}

\author{
Dewi Nurul Qomariyah \\ Fakultas tarbiyah dan Ilmu Keguruan IAIN Jember \\ dewinurul2015@gmail.com \\ Ahmad Badrus Sholihin \\ Fakultas adab dan Humaniora IAIN Jember \\ badotaman@gmail.com
}

\begin{abstract}
Petik laut ceremony is an activity undertaken by the Puger fisherman community,ethnic backgrounds, religions and culure are diverse, it makes people have particular view in doing that activity that communities are from ethnic Javanese, madurese, mandarin ethnic, and also Chinese ethnic.petik laut is a ritualceremony conducted puger fisherman community to express theirgratitude to the good, the harvest sea, sailing towards salvation in the lord and is done every os Suroor muharram month every year. The goal of the ceremony of petik laut in puger are they hope will get a lot of fishes, the safety when they were fishing and sailing. There are some contradiction between the majority of fisherman and religious leader or ulama that deal with petik laut ceremony. Most of religious leader disagree about petik laut ceremony because of the believe of the fisherman that they will get much fish when the petik laut ceremony were undertaken. Its about believe that Allah only one that give us safety and sustenance or treasure (fishes). Most of fisherman community belive that petik laut ceremony as agent to be safety and about sustenance. In contrast with most of religious leader or ulama that supposed petik laut ceremony is shirk (syirik) in Islamic religion. The contrast thougt between fisherman community and religious leader about petik laut ceremony will not become the conflict because of the awareness of them to be in good social interaction. Mutual cooperation and togetherness still alive in their community in Puger Jember.
\end{abstract}

Keywords: Contestation of Petik laut ceremony, social effect 


\section{PENDAHULUAN}

Puger saat ini sebagai kecamatan di kabupaten Jember yang meliputi dua belas desa, diantaranya desa puger kulon dan desa puger wetan. Tradisi dan budaya yang berkembang dipuger tidak dapat dilepaskan dari kondisi alam yang didominasi oleh laut. tradisi dan budaya nelayan adalah ciri khas masyarakat Puger. Masyarakat Puger merupakan masyarakat yang multikultur, diantaranya ada beberapa suku,yaitu ssuku Madura,jawa, Mandar dan china.

Petik laut adalah salah satu ritual tahunan yang dilaksanakan oleh masyarakat setempat yaitu desa Puger. masyarakat pesisir Puger hidup dengan berbagai penghayatan tradisi dan kebudayaan yang sinergis dengan keberagaman yang ada. Hal tersebut terlihat dari adanya hubungan antara agama dan budaya, dengan menggabungkan ajaran agama islam dan budaya lokal yang menjadi ciri khas masyarakat nelayan Puger . Unsur unsur penggabungan budaya lokal dan ajaran agama islam nampak terlihat dalam pembacaan tahlil, khataman al quran dan doa. Dalam prosesinya sebelum sesaji dibuang ke laut terlebih dahulu sesaji dibawa ke masjid untuk dibacakan doa doa, kemudian sesaji dipindah ke atas perahu kecil kemudian diarak ditepi pantai dan dihanyutkan ke tengah laut. Tradisi petik laut sejak lama dirayakan oleh masyarakat nelayan puger yang mayoritas beragama islam. Petik laut atau Sedekah pancer ini dilaksanakan dengan melarung sesaji dengan harapan sang pencipta memberi keselamatan kepada para nelayan Puger dan mendapat tangkapan ikan yang melimpah. Petik laut ini dilaksanakan setiap setahun sekali menjelang bulan suro atau muharrom yang difasilitasi oleh kepala desa setempat dan camat Puger. Sehingga terus dilestarikan sampai sekarang.

Budaya petik laut dimulai sejak tahun 1894. Pada waktu itu wilayah puger masih dibagi hanya beberapa desa yaitu desa puger kulon, puger wetan, lojejer, mojosari dan Grenden. Pada awalnya upacara petik laut disebut dengan labuh sesajen atau larung sesaji. larung sesaji sendiri dilaksanakan di pantai pancer yaitu daerah plawangan tempat bertemunya muara air sungai dan laut pantai selatan. daerah tersebut terkenal sangat mistis, masyarakat setempat meyakini adanya penunggu wilayah pantai Puger yang termasuk pantai selatan, sebagian masyarakat mempercayai bahwa ada beberapa pe- 
nunggu laut selatan diantaranya: nyi rorokidul, mbah sindu wongso,mbah sri anjung,nyi teges, buyut jirin serta mbah surgi. ${ }^{1}$ Nyi roro kidul dianggap sebagai penguasa laut selatan, mbah wongso adalah penggawa pangeran Puger. Mbah Sri Tanjung letak makamnya di lereng gunung watangan seki$\operatorname{tar} 3 \mathrm{~km}$ dari Puger.

Ritual petik laut merupakan budaya lokal di Puger yang lestari sampai saat ini. Ritual petik laut ini menggabungkan budaya dan sisi agama islam dalam pakteknya. Hal tersebut terlihat dari proses ritual petik laut yang diawali dengan pembacaan tahlil, doa doa dan khotmil Quran di masjid sebelum sesaji atau sesajen dilarungkan ke laut. Dalam sejarah peradaban manusia, agama dan budaya memiliki peran penting yang tidak dapat dipisahkan dalam kehidupan bermasyarakat. Hal tersebut bisa kita lihat dengan proses penyebaran islam di nusantara ratusan tahun yang lalu. Proses penyebaran tersebut di bawa oleh para ulama atau para wali melalui jalur perdagangan, dengan menggunakan cara yang bersifat tidak kontra dengan budaya, sehingga agama islam dapat diterima dengan baik oleh masyarakat setempat. Hal tersebut selaras dengan pendapat Geertz, agama adalah pattern for behavior atau pola tindakan sesuatu yang hidup dalam diri manusia dan tampak dalam kehidupan sehari hari. Agama merupakan bagian dari sistem budaya yang membekali manusia dalam melahirkan tindakan dan perilaku sehari hari. Pola dari tindakan ini terkait dengan sistem nilai, atau evaluasi, serta sistem kognitif pengetahuan manusia. hubungan antara pola bagi dan pola dari tindakan terletak ada sistem simbol yang memungkinkan pemaknaan dilakukan. $^{2}$

Keberadaan petik laut di Puger sendiri sampai saat ini masih terjadi pro dan kontra. Bagi masyarakat yang setuju terhadap budaya petik laut mereka beranggapan bahwa ritual petik laut adalah hal yang boleh dilaksanakan dengan mengharap berkah dan keselamatan bagi nelayan serta rezki yang melimpah ( tangkapan ikan yang melimpah), mereka menganggap ritual tersebut adalah sebagai sarana untuk mengungkapkan keinginannya (doa doa) agar yang mereka inginkan terkabul. Sementarara bagi sebagian masyarakat dan ulama di sekitar Puger yang kontra mereka berasumsi bahwa petik

\footnotetext{
${ }^{1}$ Dokumenatasi Data Petik Laut 2018

${ }^{2}$ Clifford Geertz, Agama Dan Kebudayaan (Yogyakarta:Kanisius, 1992), 8-9.
} 
laut adalah kesyirikan, karena masyarakat mempercayai mitos dan takhayul tentang penguasa laut pantai selatan dan mereka beranggapan dengan meminta bantuan kepada selain Allah SWT adalah syirik. Dan syirik adalah dosa besar dan Allah tidak akan mengampuninya. Ulama dan masyarakat yang tidak sependapat dengan budaya petik laut berpendapat bahwa dengan melarungkan sesaji kelaut, dan menggunakan media kepala kerbau, kepala kambing, makanan dan buah buahan adalah perbuatan yang mubadzir atau berlebih lebihan, padahal dalam ajaran syariat islam dilarang untuk melakukan perbuatan mubadzir atau isrof. Di samping itu dalam islam mengajarkan segala sesuaatu itu datangnya dari Allah, termasuk rezki, keselamatan dan musibah. Hal tersebut berkaitan dengan Tauhid sebagai ummat Islam, sehingga tidak sedikit yang kontra terhadap budaya petik laut yang ada di Puger. Berdasarkan latar belakang tersebut, Peneliti tertarik untuk mengkaji tentang adanya pro dan kontra terhadap ritual petik laut pada masyarakat nelayan Puger Jember.

\section{PEMBAHASAN}

Keberadaan petik laut di Puger sendiri sampai saat ini masih terjadi pro dan kontra. Bagi masyarakat yang setuju terhadap budaya petik laut mereka beranggapan bahwa ritual petik laut adalah hal yang boleh dilaksanakan dengan mengharap berkah dan keselamatan bagi nelayan serta rezki yang melimpah ( tangkapan ikan yang melimpah), mereka menganggap ritual tersebut adalah sebagai sarana untuk mengungkapkan keinginannya (doa doa) agar yang mereka inginkan terkabul. Sementarara bagi sebagian masyarakat dan ulama di sekitar Puger yang kontra mereka berasumsi bahwa petik laut adalah kesyirikan, karena masyarakat mempercayai mitos dan takhayul tentang penguasa laut pantai selatan dan mereka beranggapasssn dengan meminta bantuan kepada selain Allah SWT adalah syirik. Dan syirik adalah dosa besar dan Allah tidak akan mengampuninya. Ulama dan masyarakat yang tidak sependapat dengan budaya petik laut berpendapat bahwa dengan melarungkan sesaji kelaut, dan menggunakan media kepala kerbau, kepala kambing, makanan dan buah buahan adalah perbuatan yang mubadzir atau berlebih lebihan, padahal dalam ajaran syariat islam dilarang untuk melakukan perbuatan mubadzir atau isrof. Di samping itu dalam islam menga- 
jarkan segala sesuatu itu datangnya dari Allah, termasuk rezki, keselamatan dan musibah. Hal tersebut berkaitan dengan Tauhid sebagai ummat Islam, sehingga tidak sedikit yang kontra terhadap budaya petik laut yang ada di Puger.

\section{Menurut Bapak Gandul Nelayan Puger}

Saya pernah mengikuti ritual petik laut bahkan hampir setiap tahun, ada banyak sesajen yang diberikan yaitu kue, ider rider atau ayam, jukung yang dilarung nantinya. Petik laut ada semenjak zaman nenek moyang, tujuannya untuk selametan setiap tahun.Tujuan dari petik laut adalah untuk keselamatan para nelayan dan melimpahnya tangkapan ikan melimpah yang di dapat para nelayan. Dulu itu tidak ada ikan, ahirnya setelah petik laut ikan banyak, dulu waktu tidak ada petik laut ikan ikan itu "mendu" jarang ikan. semua tergantung yang kuasa, tapi Alhamdulillah dengan petik laut, ikan ikan lumayan banyak dan keluar. pada tahun 2007 dalam petik laut sesajennya kurang sehingga Sebagian masyarakat Puger banyak yang kesurupan atau ketempelan jin, kepala kambing biasanya sembelih sendiri, tapi pada waktu itu membeli, tidak menyembelih sendiri. beranggapan apabila kurang sesaji yang dilarungkan dilaut, nelayan ada yang "ketempelan" (kerasukan jin), bahkan ketika sesaji berupa ayam atau kambing tidak menyembelih sendiri, akan menimbulkan nelayan akan kerasukan jin, bahkan ketika memasak nasi tidak bisa matang. Sesaji yang dipersembahkan berupa kepala kambing, tumpeng, ayam cemani/'iber iber", aneka kue dan buah. Untuk itu petik laut adalah budaya dari zaman nenek moyang kami yang tidak bisa ditinggalkan. ${ }^{3}$

\section{Menurut Bapak Umar}

Petik laut diadakan tiap tahun tujannya untuk dapat ikan banyak, keselamatan nelayan dan juga keselamatan desa kami. Biasanya dalam petik laut menggunakan jukung (perahu kecil) untuk dilarung kelaut bersama kue kue,buah dan kepala kerbau, kambing dan tumpeng.petik laut rutin dilaksanakan setiap bulan muharrom.mulai dulu jarang ikan, ketika sudah diadakan petik laut,ikan keluar semua sehingga perekonomian kami nelayan agak lu-

\footnotetext{
${ }^{3}$ Wawancara. Gandul. 25 November 2018. Puger
} 
mayan bisa mencukupi kehidupan sehari hari kami, dalam petik laut kami masyarakat puger guyub berbondong bondong untuk membawa tumpeng dan hasil bumi, pedagan, petani dan nelayan tambah kompak, ada yang bawa air,buah buahan,ingkung dan masih banyak lagi. Petik laut sudah turun temurun dari nenekmoyang kami, sulit untuk dihapus karena kami sebagian besar nelayan harus tetap ada petik laut, kalau tidak ada,rasanya sulit karena sudah menjadi kebiasaan selama bertahun tahun dari nenek moyang. Dulu pernah ada yang mengurangi jumlah sesaji malah ikan berkurang tidak seperti biasanya. ${ }^{4}$

Dampak sosial,memang kalau pertentangan berlarut larut yakin, karena kalau kita tanyakan kepada mayoritas nelayan, petik laut ini masih Harus dilakukan, makanya tidak bisa kalau ada pemuka agama yang menjustifikasi tidak boleh, justru itu akan menimbulkan percikan percikan api tetapi bagaimana pemuka agama bisa memberikan pemahaman ini yang lebih baik.bisa terjadi konflik kalau itu dipaksakan. Darussolihin saja yang notabene pondok pesantren yang ada dipuger sini .kita tidakpernah menentang petik laut, tetapi kita memberikan pemahaman mana yang kira kira jauh dari akidah islam,ya itu yang kita sampaikan sebaiknya diperbaiki.dan Alhamdulillah perkembangan sepuluh tahun terahir ini, mulai banyak nilai nilai islamnya. Khataman, kemudian yasin, tahlil, ini rutin sudah rangkaian acara sebelum hari H. puncaknya itu larung sesaji. Jadi dikesankan larung sesaji ini memberikan sesaji untuk nyai roro kidul tapi sebetulnya tidak. Jadi sesaji itu diperebutkan.. replika kapal laut itu dilepas kemudian banyak perahu yang mengejar, jadi terjadi rebutan nanti ditengah laut itu, ini suatu yang bagus, hasilnya ini dibawa pulang. Luar biasa menarik, juga sebagai hiburan.karena merebut makanan ditengah laut sampai ada yang nyebur berenang. Wah ini malah menambah kekompakan tambah rukun sepertinya para nelayan dan yang lain. Mereka merasa senasib dalam bingkai adat istiadat yang sama. Jangan sampai keyakinan berubah masyarakat nelayan percaya dengan ruh ruh halus dan percaya.yang penting pemahaman mereka harus putus, ketika memberi sesaji kemudian diterima oleh nyi roro kidul dan ikan menjadi banyak. Justru kalau ada tokoh yang langsung menjustifikasi ini haram, ini syirik berhadapan dengan masyarakat sehingga terjadi gesekanbahkan konflik-

\footnotetext{
${ }^{4}$ Wawancara. Umar . 25 November 2018. Puger
} 
dulu pernah sampai ada, tapi konflik tidaksampai meluas kemana mana.alhamdulillah sampai sekarang masih terjalin kerukunan antara yang kontra dan ro petik laut. Toleransi itu penting antar sesame apalagi masyarakat nelayan itu rumahnya sangat berdekatan dan berdempetan. ${ }^{5}$

\section{Hasil Wawancara Ustadz Holil Asyari}

Saya kurang setuju dengan petik laut, karena bertentangan dengan syariat islam, kalau adat istiadat tidak menyimpang dari syariat saya rasa sah sah saja, akan tetapi sampai beranggapan adanya rezeki yang berlimpah agar dihindari dari bencana,ombak tinggi ini sudah keluar dari syariat.bahkan kalau ada keyakinan kesana bahwa dengan melarung sesaji bisa selamat dan rezeki banyak, itu sudah termasuk syirik. Bahkan kalau membuang makanan yang sia sia termasuk isrof dan dilarang oleh rosulullah. Yang paling penting adalah niatnya juga, kalau sampai niatnya dengan melarung sesaji ada niat supaya diberkahi rezeki dan melimpah rezekinya, selamat.ini sudah bahaya aqidahnya sudah melenceng. ditinjau dari syariatpun tidak sesuai dengan syariat islam. budaya itu boleh tapi yang tidak bertentangan dengan agama. Kalau ada ngajinya, yasin tahlil, itu hal yang positif, bahkan para tokoh agama harus mengajak mereka yang pro terhadap petik laut untuk selalu bersholawat, sholat kemasjid, dzikir bersama di setiap waktu,malah itu lebih baik,tidak hanya menunggu bulan suro atau muharram bahkan dengan tujuan tujuan tertentu. Ditinjau dari sisi sayriatdan aqidah sangat bertentangan.karena mengandung boros atau isrof seperti firman Allah. Dari aqidah bagaimana keyakinan manusia, dengan melarung sesaji rezeki semakin banyak. adalah Allah tidak butuh seperti itu. Sesuai dengan lukmanul hakim kepada anaknya berpesan agar menjauhi kemusyrikan karena kesyirikan termasuk kesesatan. ${ }^{6}$

\section{Dampak Sosial Adanya Pro Dan Kontra Petik Laut Hasil wawancara KH.Husen}

Alhamdulillah meskipun ada yang tidak setuju dengan petik laut ini, kami tetap rukun, kami sebagai tokoh masyarakat harus memberi contoh

\footnotetext{
${ }^{5}$ Wawancara, Isa Mahdi, 20 Desember 2018, Puger Jember.

${ }^{6}$ Wawancara.Holil Asyari. 20 November 2018, Puger Jember
} 
untuk tetapberbuat baikkepada mereka. Mmereka sulit untuk diarahkan agar tidak melanjutkan petik laut,alasannya karena sudah turun temurun dari nenek moyang, kami pelan pelan tetap memberikan pemahaman.dengan sentuhan dan dakwah yang lembut kami yakin pada ahirnya para nelayan pelan pelan akan berubah. Hubungan kami tetap baik,karena kami menjaganya,kami tetap saling berkunjung ketikaada hajatan, ya hablumminannas tetap harus dijaga kita tidak boleh memutus silaturrohim, tidak saling menghina,mengejek bahkan sampai bertengkar. ${ }^{7}$

Dampak sosial yang dirasakan yaitu adanya gotong royong, kebersamaan antar masyarakat contohnya membuat sesajen bareng bareng, took toko di pasar menyumbang semua, para opetani juga membantu menyumbang seikhlasnya, karena ritual petik laut dibarengi dengan sedekah desa. Dalam pelaksanaan petik laut, sikap gotong royong dan kebersamaan semakin erat meskipun ada yang pro dan kontra, kalaupun ada konflik, itu tidak sampai melebar dan tidak begitu mempengaruhi keharmonisan masyarakat dalam berhubungan social.

\section{PEMBAHASAN HASIL TEMUAN}

Budaya dan ritual petik laut di puger sangat dipengaruhi dengan adat istiadat dan agama, adanya pro dan kontra petiklaut perdebatan dan gugatan yang menegaskan bahwa adat istiadat bukan saja menjadi bagian dari ruang negosiasi atas berlakunya nilai dan praktik, tetapi juga menjadi titik penting bagi perubahan masyarakat secara mendasar dimana makna makna mengalami pergeseran dari waktu kewaktu menuju suatu arah yang bersifat perdebatan dan kontestatif, begitu pula dengan ritual petiklaut yang masih diperdebatkan antara mayoritas nelayan dan sebagian tokoh agama dan ulama, hal tersebut senada dengan pendapat dari Prof. Irwan Abdullah bahwa Pemosisian kebudayaan sebagai sistem simbol ini mengandung empat persoalan penting. pertama ,tentang batas batas dari ruang budaya yang mempengaruhi pembentukaan symbol dan makna yang di transmisikan secara historis tersebut. Berbagai bentuk ekspresi kebudayan dalam konteks ini berada dalam suatu wilayah kebudayaan yang batas batasnya mengalami suatu pergeseran yang dinamis, kedua, batas batas dari kebudyaan tersebut yang me-

\footnotetext{
${ }^{7}$ Wawancara.Kh.Husen. 20 Desember 2018, Puger Jember.
} 
nentukan konstruksi makna dipengaruhi oleh hubungan kekuasaan yang melibatkan sejumlah actor. makna dalam hal ini dibangun dan bahkan diubah dalam suatu ruang dengan serangkaian pilihan nilai dan kepentingan yang dimiliki oleh masing masing aktor. Atau agen dengan tingkat kekuasaan yang berbeda, ketiga, pola hubungan kekuasaan ini kemudian mengejewantah dalam identitas kelompok dan kelembagaan yang menjadikannya realitas objektif dan menentukan cara pandang antar kelompok, keempat, identitas yang terbentuk melalui serangkian symbol selain diterima juga menjadi objek pembicaraan, perdebatan dan gugatan yang menegaskan perubahan yang mendasar dalam batas batas kebudayaan relatif bukan saja menjadi bagian dari ruang negosiasi atas berlakunya nilai dan praktik, tetapi juga menjadi titik penting bagi perubahan masyarakat secara mendasar dimana makna makna mengalami pergeseran dari waktu kewaktu menuju suatu arah yang bersifat debatable dan kontestatif ${ }^{8}$.

\section{KESIMPULAN DAN SARAN}

\section{Kesimpulan}

Penelitian ini menunjukkan adanya dua muatan dalam satu praktik yaitu adat istiadat dan agama. Ketika Islam menjadi keyakinan dan nilai hidup dan adat istiadat menjadi kebiasaan yang ditanamkan oleh leluhur dan dipraktekkan oleh generasi berikutnya, maka nilainya keduanya menemukan bentuk dalam tradisi ritual petik laut yang eksis sampai sekarang. Penerimaan agama kemudian ditempatkan dalam lingkungan sosial tanpa melepaskan adat istiadat yang sudah berlangsung dari generasi kegenerasi selanjutnya hal tersebut terbukti dengan adanya pengajian atau khotmil quran,pembacaan yasin dan tahlil dan doa yang dilakukan sebelum acara petik laut. Sementara spiritualitas yang dibawa Islam tidak dijadikan sebagai perbedaan kultural. Tetapi dimensi agama dan budaya selanjutnya bisa bersinergi dan harmoni dalam tatanan kehidupan masyarakat dengan membentuk keyakinan melalui praktik petik laut, meskipun masih adanya pro dan kontra dngan keberadaan petik laut di Puger.

Identitas yang terbentuk melalui serangkian simbol dari adat istiadat se-

\footnotetext{
${ }^{8}$ Irwan Abdullah, Konstruksi dan Reproduksi Kebudayaan.(Yogyakarta.Pustaka Pelajar 2015) 2
} 
lain diterima juga menjadi objek pembicaraan, perdebatan dan gugatan yang menegaskan perubahan yang mendasar dalam batas batas kebudayaan relatif bukan saja menjadi bagian dari ruang negosiasi atas berlakunya nilai dan praktik, tetapi juga menjadi titik penting bagi perubahan masyarakat secara mendasar dimana makna makna mengalami pergeseran dari waktu kewaktu menuju suatu arah yang bersifat debatable dan kontestatif.begitu pula dengan ritualpetiklaut di kecamatan puger kabupaten jember, ritual tersebut telah dilakukan secara turun temurun dari nenek moyang mereka puluhan tahun yang lalu Keberadaan petik laut di Puger sendiri sampai saat ini masih terjadi pro dan kontra. Bagi masyarakat yang setuju terhadap budaya petik laut merekas beranggapan bahwa ritual petik laut adalah hal yang boleh dilaksanakan dengan mengharap berkah dan keselamatan bagi nelayan serta rezki yang melimpah ( tangkapan ikan yang melimpah), mereka menganggap ritual tersebut adalah sebagai sarana untuk mengungkapkan keinginannya (doa doa) agar yang mereka inginkan terkabul. Sementarara bagi sebagian masyarakat dan ulama di sekitar Puger yang kontra mereka berasumsi bahwa petik laut adalah kesyirikan, karena masyarakat mempercayai mitos dan takhayul tentang penguasa laut pantai selatan dan mereka beranggapan dengan meminta bantuan kepada selain Allah SWT adalah syirik. Dan syirik adalah dosa besar dan Allah tidak akan mengampuninya. Ulama dan masyarakat yang tidak sependapat dengan budaya petik laut berpendapat bahwa dengan melarungkan sesaji kelaut, dan menggunakan media kepala kerbau, kepala kambing, makanan dan buah buahan adalah perbuatan yang mubadzir atau berlebih lebihan, padahal dalam ajaran syariat islam dilarang untuk melakukan perbuatan mubadzir atau isrof. Di samping itu dalam islam mengajarkan segala sesuatu itu datangnya dari Allah, termasuk rezki, keselamatan dan musibah. Hal tersebut berkaitan dengan Tauhid sebagai ummat Islam, sehingga tidak sedikit yang kontra terhadap budaya petik laut yang ada di Puger. Disamping ada yang pro dengan petik laut ada juga sebagian tokoh masyarakat dan ulama yang kontra dengan ritual petik laut karena mereka menganggap adanya kesyirikan dalam ritual petik laut dan adanya unsur mubadzir atau isrof yang dilarang dalam agama islam.

Tradisi sebagai sarana untuk berinteraksi dan bergaul antara masyarakat satu dengan yang lainnya, tanpa tradisi pergaulan manusia akan menjadi 
hampa dan kurang bernilai,untuk itu tradisi terus dipertahankan dan dikembangkan dari zaman ke zaman dan dikembangkan hingga ke masa kini begitu juga dengan tradisi petiklaut dipuger. Manusia sebagai mahluk sosial yang selalu berinteraksi satu dengan yang lainnya dituntut untuk mengadakan perubahan perubahan tradisi yang tidak melanggar dengan tradisi leluhur mereka, dan membenahi dan disesuaikan dengan era masa kini. Ada banyak contoh ritual dan tradisi yang masih dipertahankan diera masa kini seperti petik laut yang ada di puger jember, petik laut di muncar banyuwangi dan ritual yang lainnya,tradisi tersebut masih dilestarikan sampai sekarang, dengan tradisi tersebut masyarakat bisa berinteraksi antara yang satu dengan yang lain,bekerja sama, bergotong royong dan mengedepankan rasa persaudaraan, sehingga munculah kesadaran akan nilai, norma tradisi leluhur yang berdampak positif dalam kehidupan sosial bermasyarakat. sehingga menjadi lebih bermakna. contohnya dalam pritualpetiklaut dipuger jember,masyarakat nelayan, petani dan pedagang berbaur dalam ritual petik laut yang diawali dengan selamatan desa atau sedekah desa,mereka bergotong royong membawa ambeng atau nasi, aneka hasil bumi, buah buahan, ikan dan lauk pauk serta aneka kue. Mereka berbaur bersama sama untuk mempersiapkan sedekah desa dan ritual petik laut.

Dampak sosial yang dirasakan yaitu adanya gotong royong, kebersamaan antar masyarakat contohnya membuat sesajen bareng bareng, took toko di pasar menyumbang semua, para opetani juga membantu menyumbang seikhlasnya, karena ritual petik laut dibarengi dengan sedekah desa. Dalam pelaksanaan petik laut, sikap gotong royong dan kebersamaan semakin erat meskipun ada yang pro dan kontra, kalaupun ada konflik, itu tidak sampai melebar dan tidak begitu mempengaruhi keharmonisan masyarakat dalam berhubungan sosial.

\section{Saran}

Pro dan kontra petik laut di puger menjadi bagian dari kehidupan bagi nelayan pesisir yang terkait dengan adat istiadat yang sudah terjadi seara turun temurun puluhan tahun yang lalu, bagi yang pro menganggap ritual petik laut adalah bagian yang tidak terpisahkan dengan kehidupan nelayan,bagi yang kontra terhadap ritual petik laut hal tersebut merupakan 
Dewi Nurul Qomariyah, Ahmad Badrus Solihin

adat istiadat yang banyak menyimpang dengan syariat islam, dampak bagi kehidupan sosial tidak memepengaruhi interaksi sosial,mereka tetap rukun dan saling gotong royong dalam hidup berdampingan. Penelitian ini masih banyak kekurangan untuk itu masih sangat perlu untuk diadakan penelitian lanjutan kedepannya untuk lebih menyempurnakan.

\section{DAFTAR PUSTAKA}

Clifford Geertz, Agama Dan Kebudayaan (Yogyakarta:Kanisius, 1992)

Irwan Abdullah, Konstruksi Dan Reproduksi Kebudayaan. (Yogyakarta.Pustaka Pelajar 2015)

Irwan Abdullah, Konstruksi dan Reproduksi Kebudayaan. (Yogyakarta.pustaka pelajar 201)

Muhaimin AG, Islam Dalam Bingkai Budaya Lokal Potret Dari Cirebon (Jakarta:PT.Logos Wacana Ilmu,2001)

Piotr Sztompka, Sosiologi Perubahan Sosial (Jakarta: Prenada Media Grup, 200) 